\title{
Traduire
}

Une autre perspective surita tratuction

Revue française de la traduction

$231 \mid 2014$

À table !

\section{Compte rendu : The Language of Food, Dan Jurafsky}

Hélène Ladjadj

\section{(2) OpenEdition}

Journals

Édition électronique

URL : http://journals.openedition.org/traduire/668

DOI : 10.4000/traduire.668

ISSN : 2272-9992

\section{Éditeur}

Société française des traducteurs

\section{Édition imprimée}

Date de publication : 1 décembre 2014

Pagination : 84-85

ISSN : 0395-773X

\section{Référence électronique}

Hélène Ladjadj, « Compte rendu: The Language of Food, Dan Jurafsky », Traduire [En ligne], 231 | 2014,

mis en ligne le 01 décembre 2016, consulté le 24 septembre 2020. URL : http://

journals.openedition.org/traduire/668; DOI : https://doi.org/10.4000/traduire.668 


\section{Compte rendu \\ The Language of Food, Dan Jurafsky}

Hélène Ladjadj

\section{L'histoire par le menu...}

... et la linguistique : c'est ce que nous propose Dan Jurafsky, linguiste et informaticien, professeur à l'université Stanford à Palo Alto (États-Unis), dans ce livre paru en septembre dernier.

Existe-t-il un rapport entre le toast porté lors d'un mariage et celui qui croustille au petit-déjeuner?

Pourquoi le nom de ce volatile que les Américains partagent en famille pour Thanksgiving fin novembre et les Français pour Noël évoque-t-il un pays différent (Turquie et Inde, vous aviez deviné*) selon les langues?

Peut-on évaluer le prix d'un repas en se fiant au nombre de mots que compte le menu?

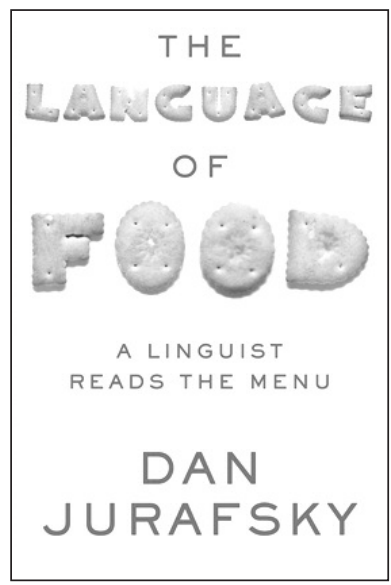

Les réponses précises et instructives à ces questions et à bien d'autres se savourent en treize chapitres formant un véritable panorama du langage de l'alimentation - recettes ancestrales, vocabulaire familier des repas quotidiens ou mots choisis par les critiques gastronomiques pour influencer leurs lecteurs.

Attention, ce livre peut modifier votre façon de percevoir ce vocabulaire, de lire la carte des restaurants et même les commentaires et conseils présents sur les emballages!

Tout commence par la question d'une enfant : " Pourquoi sur l'étiquette il y a écrit "Ketchup à la tomate", puisque c'est toujours à la tomate ? " et se déroule ensuite comme une enquête menant aux échanges, entre Orient et Occident, d'ingrédients et de recettes par le truchement des équipages des navires de commerce.

* Un indice : la réponse m'a évoqué cette perle lue sur l'étiquette d'un vêtement : «Fabriqué en Dinde » (sic) pour Made in Turkey! 
On plonge alors dans l'histoire, car ces mots familiers sont en fait des fossiles linguistiques et l'analyse des strates révèle une mine d'informations permettant de remonter le temps par l'évocation de mets raffinés appréciés, notamment, par les shahs de Perse, les princes de Provence et autres califes de Bagdad, mais aussi par les marins du Fujian ou les marchands portugais.

Ainsi la langue de l'alimentation met en évidence les liens indiscutables déjà présents entre les civilisations il y a des centaines ou des milliers d'années, mais pour D. Jurafsky, elle est également un code qui permet de mieux décrypter le présent. L'auteur et son équipe ont étudié différents types de textes soumis à divers filtres; le corpus inclut notamment une vaste collection de menus (numérisés par la New York Public Library) et des critiques, commentaires et publicités concernant des restaurants, des marques et des produits alimentaires.

Linguistique, histoire, psychologie, sociologie : l'exploration de ce domaine tisse un réseau très dense d'une richesse impressionnante, dans lequel on se promène avec beaucoup de plaisir, mené par un guide passionnant, au fil de chapitres classés dans l'ordre du repas: menu, entrée... et contenant même des recettes! Un régal (et du grain à moudre pour les traducteurs éventuels)!

hladjadj@gmail.com

Dan Jurafsky, The Language of Food: A Linguist Reads the Menu, W. W. Norton \& Company, New York (États-Unis), 2014.

Blog de l'auteur (en anglais) : http://languageoffood.blogspot.fr/ 